\title{
Carbonyl Emissions from Gasoline and Diesel Motor Vehicles
}

IChris A. Jakobert, 2Michael A. Robert, 3Sarah G. Riddles, IHugo Destaillats

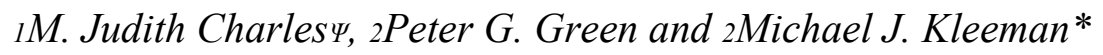

1Department of Environmental Toxicology, 2Department of Civil and Environmental Engineering, 3Department of Chemistry, University of California, Davis, One Shields Avenue, Davis, CA 95616

$\Psi$ Deceased

$\uparrow$ Present address: Research Division, California Air Resources Board, Sacramento, CA 95812

$\Omega$ Present address: SAES Pure Gas, Inc., San Luis Obispo, CA 93401

¥ Present address: Environmental Energy Technologies Division, Lawrence Berkeley National Laboratory, Berkeley, CA 94720

cajakober@ucdavis.edu

RECEIVED DATE

*mjkleeman@ucdavis.edu, (530)-752-8386

\begin{abstract}
Carbonyls from gasoline powered light-duty vehicles (LDVs) and heavy-duty diesel powered vehicles (HDDVs) operated on chassis dynamometers were measured using an annular denuder-quartz filter-polyurethane foam sampler with $O$-(2,3,4,5,6pentafluorobenzyl)hydroxylamine derivatization and chromatography-mass spectrometry analyses. Two internal standards were utilized based on carbonyl recovery, 4fluorobenzaldehyde for $<\mathrm{C}_{8}$ carbonyls and 6-fluoro-4-chromanone for $\geq \mathrm{C}_{8}$ compounds. Gas- and particle-phase emissions for 39 aliphatic and 20 aromatic carbonyls ranged from $0.1-2000 \mu \mathrm{g} / \mathrm{L}$ fuel for LDVs and $1.8-27000 \mu \mathrm{g} / \mathrm{L}$ fuel for HDDVs. Gas-phase species accounted for $81-95 \%$ of the total carbonyls from LDVs and $86-88 \%$ from HDDVs. Particulate carbonyls emitted from a HDDV under realistic driving conditions were similar to concentrations measured in a diesel particulate matter (PM) standard reference material. Carbonyls accounted for $19 \%$ of particulate organic carbon (POC) emissions from low-emission LDVs and 37\% of POC emissions from three-way catalyst equipped
\end{abstract}


LDVs. This identifies carbonyls as one of the largest classes of compounds in LDV PM emissions. The carbonyl fraction of HDDV POC was lower, 3.3-3.9\% depending upon operational conditions. Partitioning analysis indicates the carbonyls had not achieved equilibrium between the gas- and particle-phase under the dilution factors of 126-584 used in the current study.

\section{INTRODUCTION}

Atmospheric aerosols have numerous environmental impacts (I) including human health effects (2). Aerosol toxicity mechanisms remain under investigation, but previous research finds an association between toxicity and particle size and composition (3-6). Chemical speciation of aerosols emitted by dominant sources, such as motor vehicles (79 ), is necessary to identify those compounds and sources that may be linked to human health effects.

The majority of airborne particulate matter (PM) released from motor vehicles is composed of compounds whose structures are largely unknown despite extensive efforts (10-13). Carbonyls are one example of an abundant class of compounds in motor vehicle emissions that are incompletely characterized. In studies that examined carbonyls, chemical analyses typically involved derivatization with either 2,4dinitrophenylhydrazine (DNPH) or $O$-(2,3,4,5,6-pentafluorobenzyl)hydroxylamine (PFBHA). The carbonyl hydrazones or oximes undergo chemical analysis with a combination of either gas or liquid chromatography followed by mass spectrometry or absorption spectroscopy, see for example (14-17). Carbonyls have been measured in vehicle emissions using DNPH impregnated cartridges $(10,12,13,18,19)$, however the method cannot distinguish between gas- and particle-phase emissions. Previous laboratory studies examining photo-oxidation reaction products utilized annular denuders in conjunction with filter substrates to examine both gas- and particle-phase carbonyl species (20-22), but the approach has not been applied to motor vehicle emissions. Carbonyls are known to directly influence physiological response to diesel exhaust particles (23) and can form oligomers that contribute to secondary organic aerosol formation (24). Thus, more thorough characterization of carbonyl emissions provides valuable information about the environmental impact of motor vehicles.

In the current study we describe measurements of gas- and particle-phase carbonyls emissions from light-duty gasoline (LDV) and heavy-duty diesel (HDDV) motor vehicles operated on a chassis dynamometer under realistic driving cycles. Diluted emissions were collected using an annular denuder-quartz filter-polyurethane foam (PUF) sampling system. Chemical analyses used PFBHA derivatization in conjunction with gas chromatography - ion trap mass spectrometry (GC-ITMS) and high performance liquid chromatography - ion trap mass spectrometry (HPLC-ITMS). This sampling approach does not measure the most volatile and abundant gas-phase carbonyls species (formaldehyde and acetaldehyde) due to their high vapor pressure and poor retention by the annular denuders. Instead, this study focuses on less-volatile carbonyls that are important for health effects due to their ability to penetrate deep into the human respiratory system via airborne particles. Emission factors of 59 carbonyls from gasoline and diesel engines are reported, the results are compared to a diesel PM standard reference material (SRM) and the observed phase distributions are examined. 


\section{Materials}

\section{EXPERIMENTAL SECTION}

The majority of carbonyl standards, XAD-4 polystyrene resin and PFBHA were obtained from Sigma-Aldrich (Milwaukee, WI). Benzaldehyde was purchased from Acros Organics (Beel, Belgium), d6-benzaldehyde (d6-BZA) from Cambridge Isotope Laboratories (Andover, MA) and authentic standards for several compounds were donated by Midwest Research Institute (Kansas City, MO). Methanol (MeOH, purge and trap grade) and diethyl ether ( $\mathrm{Et}_{2} \mathrm{O}$, anhydrous ACS grade) were obtained from Fisher Scientific (Fairlawn, NJ). Burdick and Jackson acetonitrile (ACN, carbonyl-free), hexane (trace analysis grade) and dichloromethane (DCM, trace analysis grade) were obtained from VWR International (West Chester, PA).

\section{Chemical Analysis}

Sample Extraction/Derivatization: Filter samples, and a $2 \mathrm{mg}$ quantity of National Institute of Standards and Technology (NIST) diesel PM SRM 1650, were extracted in triplicate with ultrasonic agitation using 1:1 hexane:DCM (v/v) followed with $\mathrm{MeOH}$. Similarly, denuders and PUF substrates were extracted in triplicate with hexane:DCM followed by $\mathrm{MeOH}$. Extracts were reduced in volume to $<50 \mu \mathrm{L}$, to which a 9:1 (v/v) mixture of ACN:DCM was added to increase the volume to $200 \mu \mathrm{L}$. A $200 \mathrm{mM}$ solution of PFBHA in $\mathrm{MeOH}$ was added for derivatization to target PFBHA concentrations of 5 $\mathrm{mM}$ for GC analysis and $10 \mathrm{mM}$ for HPLC analysis. Samples and two sets of multi-point calibration standards were derivatized at room temperature for 24 hours. One set of calibration standards was analyzed immediately preceding, and the other immediately following, the extracts. See Jakober et al. for further details $(16,25)$.

The necessity for different PFBHA concentrations arose during analytical method development where both the mono- and dioxime of dicarbonyls were observed, see an example in Figure S1. Four different concentrations of PFBHA were evaluated with 25 model carbonyls, described in detail within Supporting Information. Monocarbonyls were found to exhibit a substantial increase in response from $5 \mathrm{mM}$ vs. $2 \mathrm{mM}$ PFBHA, which then typically decreased for both 10 and $20 \mathrm{mM}$ concentrations, GC responses for each compound are shown in Figure S2. Dicarbonyls were observed to have the greatest response and more complete derivatization at the $10 \mathrm{mM}$ PFBHA concentration, shown in Figure S3 for both GC and LC analyses. Since GC analysis focuses on smaller monocarbonyls and HPLC provides analysis of larger dicarbonyls the concentrations of 5 and $10 \mathrm{mM}$ were utilized respectively.

Chromatography-Mass Spectrometry: Analytes were separated using a J\&W DBXLBMSD capillary column in a Varian 3400 GC followed by analysis using a Varian 2000 ITMS operated with both electron ionization ( $3 \mu \mathrm{L}$ injection volume) and methane chemical ionization (5 $\mu \mathrm{L}$ injection). An Agilent 1100 HPLC-ITMS using atmospheric pressure chemical ionization (APCI) with a Phenomenex Prodigy $\mathrm{C}_{18}$ chromatographic column was used to separate $10 \mu \mathrm{L}$ injection volumes using a 40 to $95 \%$ water:MeOH gradient. Carbonyls were quantified using their most abundant PFBHA oxime isomer peak. Additional details of GC-ITMS and HPLC-ITMS analysis are described elsewhere 
$(16,25)$.

Internal Standard Optimization: Initial experiments showed the recovery efficiency of model carbonyls spiked on quartz filters (see Figure S4) varied substantially depending on compound vapor pressure and choice of internal quantification standard (IS), 2,2'difluorobiphenyl (DFB) or 4-fluorobenzaldehyde (4-FBZA) and 2-fluoro-9-fluorenone (2-FFLN), which form PFB oximes. DFB provided poor recoveries over the range of compound vapor pressures examined. The higher volatility carbonyls were better represented using 4-BZA, however this IS produced excessive recoveries for lower volatility compounds. Utilizing 2-FFLN produced more acceptable recoveries for the less volatile carbonyls. Given this initial finding an additional experiment was conducted evaluating IS selection on carbonyl recovery. Annular denuder substrates $(\mathrm{n}=4)$ were spiked with sixteen model carbonyls, ranging from $\mathrm{C}_{4}-\mathrm{C}_{14}$, to yield targeted chemical analysis concentrations of $1 \mathrm{ng} \mu \mathrm{L}-1$. The spiking solvent was allowed to evaporate prior to solvent extraction and reduction.

Recovery efficiency using four different internal standards for quantification are presented in Figure 1. Similar recoveries were observed for compounds $<\mathrm{C} 8$ using 4FBZA and d6- BZA, typically $60-100 \%$. 4-Fluorobenzaldehyde was selected for the quantification internal standard for carbonyls $<\mathrm{C} 8$ due to the slightly enhanced response observed and its chromatographic separation from benzaldehyde. Substantial differences were observed for carbonyls $>\mathrm{C}_{8}$ when using 6-fluoro-4-chromanone (6-FCR) and 2FFLN for quantification. Even though 6-FCR yielded greater variability, as observed by the larger standard deviations, it produced higher recoveries (typically between 70-115\%) relative to 2-FFLN (typically between 45-94\%) leading to its selection for quantification of carbonyls $\geq \mathrm{C} 8$.

\section{Sample Collection}

The emission collection methodology was similar to that used by Schauer et al. $(12,13)$, and is detailed elsewhere $(16,25,26)$. Briefly, the sampling train consisted of a $\mathrm{PM}_{2.5}$ (particulate matter, $\mathrm{D}_{\mathrm{p}}<2.5 \mu \mathrm{m}$ ) cyclone preceding eight-channel annular denuders in series (URG, Chapel Hill, NC) followed by $47 \mathrm{~mm}$ quartz fiber filters (Pall Gelman, Ann Arbor, MI) and two PUF (URG) substrates in series. The annular denuders were coated with XAD-4 polystyrene resin (27). To minimize organic contaminants quartz filters were baked at $550^{\circ} \mathrm{C}$ for +12 hours and PUF media were Soxhlet extracted with 9:1 (v/v) hexane: $\mathrm{Et}_{2} \mathrm{O}$ and dried with organic-free nitrogen.

Light-duty gasoline vehicles (LDVs): LDV emissions were collected at the Haagen-Smit Laboratory (HSL) in El Monte, CA during August-September 2002 (28). Vehicles were operated on a chassis dynamometer using the Federal Test Procedure (FTP) driving cycle. HSL staff measured the $\mathrm{CO}_{2}$ emissions using Horiba AIA 210 and AIA 220 infrared analyzers (Ann Arbor, MI). Multiple vehicles within a technology class were composited on each set of sampling media to obtain sufficient mass for the analyses (28). The LDV technology classes reported in this research include low emission vehicles (LEV) and three-way catalyst equipped vehicles (TWC). 
Heavy-duty diesel vehicles (HDDVs): Emission samples were collected from HDDVs in Riverside, CA during June 2003 (29). HDDVs were driven on a transportable chassis dynamometer operated by West Virginia University (WVU). WVU staff measured the $\mathrm{CO}_{2}$ emissions using a Rosemount Analytical Model 880A non-dispersive infrared analyzer (Berenyi, Hungary). Vehicle inertial load of 56,000 lbs. was simulated using flywheels and electrical motor resistance. Vehicles were tested under a 5-mode driving cycle (HHDDT, Heavy Heavy-Duty Diesel Truck) consisting of a 30 minute idle, 17 minute creep, 11 minute transient stage and two cruise stages of 34 and 31 minutes, with a top speed of 65 miles hour-1 for the second cruise (30). The HDDV emissions reported here were obtained from a 1999 Freightliner tractor with a 500 horsepower engine, and 138,553 miles travelled. In addition to the full test cycle, this vehicle was also sampled while operating under six replications of only the idle and creep modes of the test cycle, hereafter referred to as Idle-creep.

\section{Emission Factors and Speciation}

\section{RESULTS}

Due to the polar and volatile nature of the targeted carbonyls, extraction efficiency was examined for an extensive set of surrogates (see Table S1). Surrogate recoveries fall between $60-120 \%$ for all compounds on all sampling media, except for underivatized 4fluorobenzophenone. Reported emission factors were corrected for observed extraction efficiencies as described previously (25).

A total of 59 carbonyls, 39 aliphatic and 20 aromatic, were quantified. Aliphatic aldehydes including butanal and hexanal were the most abundant carbonyl class. Dicarbonyls including methyl glyoxal and 2,3-hexanedione were the next most abundant carbonyl class. Ten of the aromatic carbonyls were found solely in the gas-phase.

Particle- and gas-phase emission factors for the observed carbonyls are presented in Table 1, including representative chemical structures, after normalizing by fuel consumption and accounting for the effects of dilution and background subtraction (25, 28, 29). Fuel consumption was calculated using $\mathrm{CO}_{2}$ emissions assuming 2.28 and 2.77 ( $\mathrm{kg} \mathrm{CO}_{2} \mathrm{emitted} / \mathrm{L}$ fuel) for oxygenated gasoline and diesel fuel, respectively (34).

HDDV carbonyl emissions were much greater than LDV emissions on a fuel consumption basis. Within the HDDV class the Idle-creep emissions were much larger than HHDDT emissions, consistent with results from Sawant et al. (32), suggesting that HDDV operation under higher load leads to more complete combustion/oxidation, hence less carbonyl formation. This is supported by the increased dicarbonyl abundance in the HHDDT particle emissions versus the higher aliphatic aldehyde content of the Idle-creep particle emissions (see Figure 2).

\section{Phase Distribution}

Figure 2 shows that gas-phase species accounted for $\sim 95 \%$ of the LEV and $\sim 81 \%$, of the TWC measured carbonyl emissions, which excluded formaldehyde and acetaldehyde. The 1999 Freightliner emissions were similar, containing 88\% and $86 \%$ gas-phase carbonyls for the Idle-creep and HHDDT conditions respectively. Gas-phase carbonyl 
emissions are dominated by aliphatic aldehydes, dicarbonyls, and aromatic aldehydes. The particle-phase emissions show a relative reduction in aliphatic aldehydes and an increase in dicarbonyl content. The HDDV emissions show dramatic reductions in abundance of aromatic aldehydes and increases in the relative abundance of unsaturated aliphatic carbonyls for the particle-phase emissions.

While gas-phase carbonyls account for the majority of total carbonyl emissions, the condensed species still account for a significant fraction of particulate organic carbon (POC) mass at the sampled dilution conditions. Figure 3 shows the measured carbonyls account for $19 \%$ of total POC emissions from LEVs and $37 \%$ of POC emissions from TWCs in the current study, making carbonyls one of the largest classes of compound identified in LDV PM to date. Carbonyls accounted for 3.3-3.9\% of the HDDV POC depending upon operation conditions. Note that these values neglect any possible contribution of formaldehyde and acetaldehyde to POC emissions. The greater semivolatile carbonyl content of particulates from LDVs versus those from HDDVs is consistent with previous observations that found particles of greater volatility near freeways with only LDV traffic (35) versus particles near freeways with significant HDDV traffic (36).

\section{DISCUSSION}

\section{Quality Assurance and Comparison to Previous Measurements}

Measurement of polycyclic aromatic hydrocarbon concentrations in these particulate emission samples and NIST SRM 1650 extracts following the extraction techniques described above agree well with values obtained by several other laboratories (26). Figure 4 shows that most carbonyl mass concentrations measured in the NIST SRM 1650 are in excellent agreement with the emissions from the 1999 Freightliner $(56,000$ pound load, HHDDT driving cycle), with most carbonyls agreeing within a factor of two or better, data in Table S2. The similarity between carbonyl concentrations in the fresh emissions vs. the NIST SRM suggests that carbonyl compounds were stable during sample collection. Additional confidence is provided by the precision of carbonyl mass collected by parallel denuders during the HDDV sampling (shown in Figure S5). Measured carbonyl emissions are within a factor of 0.27 to 1.38 (average $=0.68$ ) for the 1999 HHDDT and 0.19 to 5.7 (average $=1.3$ ) for the 1999 Idle-creep parallel denuder sampling trains.

Total carbonyl emission rates measured in the present study are typically lower than previously measured values $(12,13,18,19,31-33)$ when results are presented per distance traveled (see Figure S6). Better agreement was found when results are presented per unit of emitted particulate matter (see Figure S7). These trends reflect the newer vehicles, fuel compositions and engine technologies examined in the current study, which produce lower emissions.

Temime et al. reported low collection efficiencies for select carbonyls using annular denuders (22) which could bias the phase distribution measurements. These artifacts are unlikely in the current study due to significant differences in the collection methodology: (a) two eight-channel denuders (285 mm length) in series were used here vs. single five- 
channel denuder (242 mm length), (b) lower flow rate here (16.7 vs. $20 \mathrm{~L} / \mathrm{min})$, and (c) lower concentrations sampled in the current study (low pptr vs. 30-230 ppb). Analytical procedures in the current study included the use of surface-deactivated glassware, organic solvents (not water), and higher concentrations of PFBHA vs. the impinger analysis, which minimize sorption losses and enhance derivatization efficiency.

\section{Gas-Particle Partitioning}

Carbonyl gas-particle partitioning behavior was examined using a PAH partitioning framework developed for ambient aerosols (37). Since the observed partitioning may be associated with collection conditions a summary of the sample collection temperature, relative humidity and dilution ratio for each sample are provided in Table S3. Collection conditions for the LDV emissions averaged $27^{\circ} \mathrm{C}, 74 \%$ relative humidity and a dilution factor of 126 . The HDDV collection conditions ranged from $33-40{ }^{\circ} \mathrm{C}, 39-49 \%$ relative humidity and dilution factor of 167 and 584 for the HHDDT and Idle-creep tests respectively. The partitioning coefficient $\left(\mathrm{K}_{\mathrm{p}, \mathrm{om}}\right)$ is defined as:

$$
\mathrm{K}_{\mathrm{p}, \mathrm{om}}=\mathrm{C}_{\mathrm{p}} /\left(\mathrm{TSP} \times \text { fom } \mathrm{x} \mathrm{Cg}_{\mathrm{g}}\right)
$$

where $\mathrm{Cp}_{\mathrm{p}}$ is the particle-phase concentration, $\mathrm{Cg}$ the gas-phase concentration TSP the total particulate concentration and fom is the fraction of organic material in the particle phase $(38-40)$.

Calculated partitioning coefficients within each vehicle category are similar in magnitude for almost all species within each compound class, but do not follow the expected equilibrium behavior as a function of compound vapor pressure, as displayed in Figure S8. This trend likely indicates that the carbonyls had not attained complete equilibrium under the test conditions.

The ratio of mass observed on the PUF substrates to the total particulate carbonyls was calculated to further characterize the semi-volatile nature of the compounds, and presented in Figure S9. In general, as the volatility of the carbonyl decreased so did the PUF/total particulate carbonyl ratio. A few exceptions were observed for some higher volatility carbonyls, which may be biased by denuder breakthrough creating an artificially high filter carbonyl measurement. The decrease in the PUF/total particulate carbonyl ratio with decreasing volatility likely reflects the tendency for the more volatile carbonyls to evaporate from particles collected on the filter. This agrees with previous results from Lipsky and Robinson (41) showing loss of semi-volatile species from diesel emission particles with increasing dilution.

The results of the current study represent a snapshot in time for the behavior of semivolatile carbonyls as they undergo dilution after emission. Carbonyls account for a significant fraction of the emitted PM and the semi-volatile behavior observed in this study explains several field observations that have been made without the benefit of detailed chemical characterization.

\section{ACKNOWLEDGEMENTS}

This research was supported by the California Air Resources Board, under contract \#०๑-318, the National Science Foundation Integrative Graduate Education, Research, and Training Award \# DGE-9972741, and the 
National Institute of Environmental Health Sciences PHS grant T32 ES07059. The authors thank staff of the California Air Resources Board and West Virginia University Transportable Heavy-duty Emissions Testing Laboratory for assistance with sample collection, Dr. Thomas Young for analytical instrumentation, Dr. Lara Gundel for denuder assistance, Drs. Roger Atkinson and Janet Arey and staff of the Air Pollution Research Center at the University of California, Riverside for laboratory and fume hood space during sample collection. All work at LBNL was conducted under US DOE Contract No. DE-ACO2-05CH11231.

\section{SUPPORTING INFORMATION AVAILABLE}

Additional materials pertinent to the sample collection conditions, optimization of PFBHA concentration, quality assurance, comparison to previous results and examination of observed carbonyl partitioning are provided. This information is available free of charge via the Internet at http://pubs.acs.org.

\section{REFERENCES}

(1) Poschl, U. Atmospheric aerosols: Composition, transformation, climate and health effects. Angew. Chem. 2005, 44 (46), 7520-7540.

(2) Pope, C. A. Review: Epidemiological basis for particulate air pollution health standards. Aerosol Sci. Tech. 2000, 32 (1), 4-14.

(3) Claiborn, C. S.; Larson, T.; Sheppard, L. Testing the metals hypothesis in Spokane, Washington. Environ. Health Persp. 2002, 110, 547-552.

(4) Grahame, T.; Hidy, G. Using factor analysis to attribute health impacts to particulate pollution sources. Inhal. Toxicol. 2004, 16, 143-152.

(5) McDonald, J. D.; Eide, I.; Seagrave, J.; Zielinska, B.; Whitney, K.; Lawson, D. R.; Mauderly, J. L. Relationship between composition and toxicity of motor vehicle emission samples. Environ. Health Persp. 2004, 112 (15), 1527-1538.

(6) Salonen, R. O.; Halinen, A. I.; Pennanen, A. S.; Hirvonen, M. R.; Sillanpaa, M.; Hillamo, R.; Shi, T. M.; Borm, P.; Sandell, E.; Koskentalo, T.; Aarnio, P. Chemical and in vitro toxicologic characterization of wintertime and springtime urban-air particles with an aerodynamic diameter below $10 \mu \mathrm{m}$ in Helsinki. Scand. J. Work Env. Hea. 2004, 30, $80-90$.

(7) Schauer, J. J.; Cass, G. R. Source apportionment of wintertime gas-phase and particlephase air pollutants using organic compounds as tracers. Environ. Sci. Technol. 2000, 34 (9), 1821-1832.

(8) Schauer, J. J.; Fraser, M. P.; Cass, G. R.; Simoneit, B. R. T. Source reconciliation of atmospheric gas-phase and particle-phase pollutants during a severe photochemical smog episode. Environ. Sci. Technol. 2002, 36 (17), 3806-3814.

(9) Zheng, M.; Cass, G. R.; Schauer, J. J.; Edgerton, E. S. Source apportionment of PM2.5 in the southeastern United States using solvent-extractable organic compounds as tracers. Environ. Sci. Technol. 2002, 36 (11), 2361-2371.

(10) McDonald, J. D.; Barr, E. B.; White, R. K.; Chow, J. C.; Schauer, J. J.; Zielinska, B.; 
Grosjean, E. Generation and characterization of four dilutions of diesel engine exhaust for a subchronic inhalation study. Environ. Sci. Technol. 2004, 38 (9), 2513-2522.

(11) Rogge, W. F.; Hildemann, L. M.; Mazurek, M. A.; Cass, G. R.; Simoneit, B. R. T. Sources of fine organic aerosol 2. Noncatalyst and catalyst-equipped automobiles and heavy-duty diesel trucks. Environ. Sci. Technol. 1993, 27 (4), 636-51.

(12) Schauer, J. J.; Kleeman, M. J.; Cass, G. R.; Simoneit, B. R. T. Measurement of emissions from air pollution sources. 2. C-1 through C-30 organic compounds from medium duty diesel trucks. 1999, 33 (10), 1578-1587.

(13) Schauer, J. J.; Kleeman, M. J.; Cass, G. R.; Simoneit, B. R. T. Measurement of emissions from air pollution sources. 5. C-1-C-32 organic compounds from gasolinepowered motor vehicles. Environ. Sci. Technol. 2002, 36 (6), 1169-1180.

(14) Druzik, C. M.; Grosjean, D.; Vanneste, A.; Parmar, S. S. Sampling of atmospheric carbonyls with small Dnph-coated C18 cartridges and liquid-chromatography analysis with diode-array detection. Int. J. Environ. An. Ch. 1990, 38 (4), 495-512.

(15) Grosjean, E.; Green, P. G.; Grosjean, D. Liquid chromatography analysis of carbonyl (2,4-dinitrophenyl)hydrazones with detection by diode array ultraviolet spectroscopy and by atmospheric pressure negative chemical ionization mass spectrometry. Anal. Chem. 1999, 71 (9), 1851-1861.

(16) Jakober, C. A.; Charles, M. J.; Kleeman, M. J.; Green, P. G. LC-MS analysis of carbonyl compounds and their occurrence in diesel emissions. Anal. Chem. 2006, 78 (14), 5086-5093.

(17) Lelacheur, R. M.; Sonnenberg, L. B.; Singer, P. C.; Christman, R. F.; Charles, M. J. Identification of carbonyl-compounds in environmental-samples. Environ. Sci. Technol. 1993, 27 (13), 2745-2753.

(18) Grosjean, D.; Grosjean, E.; Gertler, A. W. On-road emissions of carbonyls from light-duty and heavy-duty vehicles. Environ. Sci. Technol. 2001, 35 (1), 45-53.

(19) Kristensson, A.; Johansson, C.; Westerholm, R.; Swietlicki, E.; Gidhagen, L.; Wideqvist, U.; Vesely, V. Real-world traffic emission factors of gases and particles measured in a road tunnel in Stockholm, Sweden. Atmos. Environ. 2004, 38, 657-673.

(20) Kleindienst, T. E.; Conver, T. S.; McIver, C. D.; Edney, E. O. Determination of secondary organic aerosol products from the photooxidation of toluene and their implications in ambient PM2.5. J. Atmos. Chem. 2004, 47 (1), 79-100.

(21) Yu, J. Z.; Cocker, D. R.; Griffin, R. J.; Flagan, R. C.; Seinfeld, J. H. Gas-phase ozone oxidation of monoterpenes: Gaseous and particulate products. J. Atmos. Chem. 1999, 34 (2), 207-258.

(22) Temime, B.; Healy, R. M.; Wenger, J. C. A denuder-filter sampling technique for the detection of gas and particle phase carbonyl compounds. Environ. Sci. Tech. 2007, 41 (18), 6514-6520.

(23) Madden, M. C.; Dailey, L. A.; Stonehuerner, J. G.; Harris, D. B. Responses of cultured human airway epithelial cells treated with diesel exhaust extracts will vary with the engine load. J. Toxicol. Env. Heal. A 2003, 66, 2281-2297. 
(24) Loeffler, K. W.; Koehler, C. A.; Paul, N. M.; De Haan, D. O. Oligomer formation in evaporating aqueous glyoxal and methyl glyoxal solutions. Environ. Sci. Tech. 2006, 40 (20), 6318-6323.

(25) Jakober, C. A.; Riddle, S. G.; Robert, M. A.; Destaillats, H.; Charles, M. J.; Green, P. G.; Kleeman, M. J. Quinone emissions from gasoline and diesel motor vehicles. Environ. Sci. Tech. 2007, 41 (13), 4548-4554.

(26) Riddle, S. G.; Jakober, C. A.; Robert, M. A.; Cahill, T. M.; Charles, M. J.; Kleeman, M. J. Large PAHs detected in the fine particulate matter emitted from light-duty gasoline vehicles. Atmos. Environ. 2007, 41 (38), 8658-8668.

(27) Gundel, L. A.; Lee, V. C.; Mahanama, K. R. R.; Stevens, R. K.; Daisey, J. M. Direct determination of the phase distributions of semivolatile polycyclic aromatichydrocarbons using annular denuders. Atmos. Environ. 1995, 29 (14), 1719-1733.

(28) Robert, M. A.; Jakober, C. A.; VanBergen, S.; Kleeman, M. J. Size and composition distribution of particulate matter 1. Light-duty gasoline vehicles. J. Air Waste Manage. 2007, 57, 1414-1428.

(29) Robert, M. A.; Jakober, C. A.; Kleeman, M. J. Size and composition distribution of particulate matter 2. Heavy-duty diesel vehicles. J. Air Waste Manage. 2007, 57, 14291438.

(30) Gautam, M.; Clark, N.; Riddle, W.; Nine, R.; Wayne, W. S.; Maldonado, H.; Agrawal, A.; Carlock, M. Development and initial use of a heavy-duty diesel truck test schedule for emissions characterization. SAE Tech. Paper Series 2002, SP-1715 (200201-1753).

(31) Mabilia, R.; Cecinato, A.; Guerriero, E.; Possanzini, M. Uncertainties of polynuclear aromatic hydrocarbon and carbonyl measurements in heavy-duty diesel emission. J. Sep. Sci. 2006, 29 (2), 302-307.

(32) Sawant, A. A.; Shah, S. D.; Zhu, X. N.; Miller, J. W.; Cocker, D. R. Real-world emissions of carbonyl compounds from in-use heavy-duty diesel trucks and diesel BackUp Generators (BUGS). Atmos. Environ. 2007, 41 (21), 4535-4547.

(33) Staehelin, J.; Keller, C.; Stahel, W.; Schlapfer, K.; Wunderli, S. Emission factors from road traffic from a tunnel study (Gubrist tunnel, Switzerland). Part III: Results of organic compounds, SO2 and speciation of organic exhaust emission. Atmos. Environ. 1998, 32 (6), 999-1009.

(34) USDOE Documentation for Emissions of Greenhouse Gases in the United States 2002; DOE/EIA-0638(2002). Office of Integrated Analysis and Forecasting, U.S. Department of Energy: Washington D.C., 2004.

(35) Kuhn, T.; Biswas, S.; Fine, P. M.; Geller, M.; Sioutas, C. Physical and chemical characteristics and volatility of PM in the proximity of a light-duty vehicle freeway. Aerosol Sci. Tech. 2005, 39 (4), 347-357.

(36) Biswas, S.; Ntziachristos, L.; Moore, K. F.; Sioutas, C. Particle volatility in the vicinity of a freeway with heavy-duty diesel traffic. Atmos. Environ. 2007, 41 (16), 34793493. 
(37) Yamasaki, H.; Kuwata, K.; Miyamoto, H. Effects of ambient-temperature on aspects of airborne polycyclic aromatic-hydrocarbons. Environ. Sci. Technol. 1982, 16 (4), 189194.

(38) Liang, C. K.; Pankow, J. F. Gas/particle partitioning of organic compounds to environmental tobacco smoke: Partition coefficient measurements by desorption and comparison to urban particulate material. Environ. Sci. Technol. 1996, 30 (9), 2800-2805.

(39) Liang, C. K.; Pankow, J. F.; Odum, J. R.; Seinfeld, J. H. Gas/particle partitioning of semivolatile organic compounds to model inorganic, organic, and ambient smog aerosols. Environ. Sci. Technol. 1997, 31 (11), 3086-3092.

(40) Mader, B. T.; Pankow, J. F. Study of the effects of particle-phase carbon on the gas/particle partitioning of semivolatile organic compounds in the atmosphere using controlled field experiments. Environ. Sci. Technol. 2002, 36 (23), 5218-5228.

(41) Lipsky, E. M.; Robinson, A. L. Effects of dilution on fine particle mass and partitioning of semivolatile organics in diesel exhaust and wood smoke. Environ. Sci. Technol. 2006, 40 (1), 155-162.

\section{Figure Captions}

Figure 1. Comparison of model carbonyl extraction efficiency from annular denuders $(n=4)$ as the mean \pm standard deviation percent recovery determined using GCITMS with different internal standards for A) compounds $<\mathrm{C}_{8}$ using 4fluorobenzaldehyde and d6-benzaldehyde and B) compounds $>\mathrm{C} 8$ using 6-fluoro4-chromanone and 2-fluoro-9-fluorenone.

Figure 2. Carbonyl speciation for light-duty gasoline and heavy-duty diesel vehicles operated on chassis dynamometers.

Figure 3. Particulate carbonyl emissions as a percentage of total particulate matter (PM) and particulate organic carbon (OC) emissions for light-duty gasoline (LEV, TWC) and heavy-duty diesel vehicles (99 HHDDT, 99 Idle-creep).

Figure 4. Comparison of the carbonyl composition ( $\mathrm{ppm}$ ) of diesel particulate matter for the NIST 1650 SRM and emissions from a 1999 Freightliner operated under the HHDDT driving cycle.

\section{Figure 1}



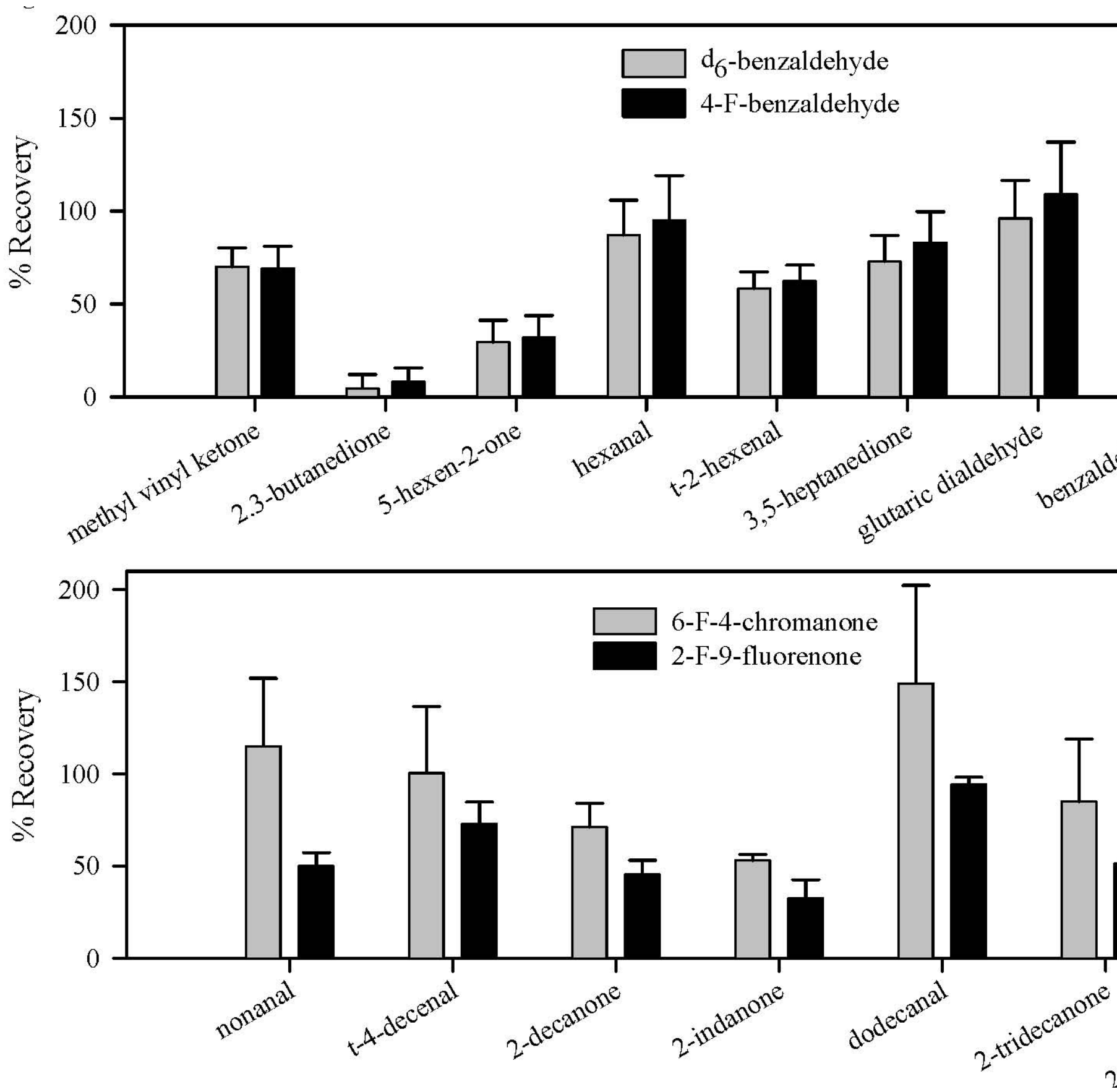

Figure 2. 


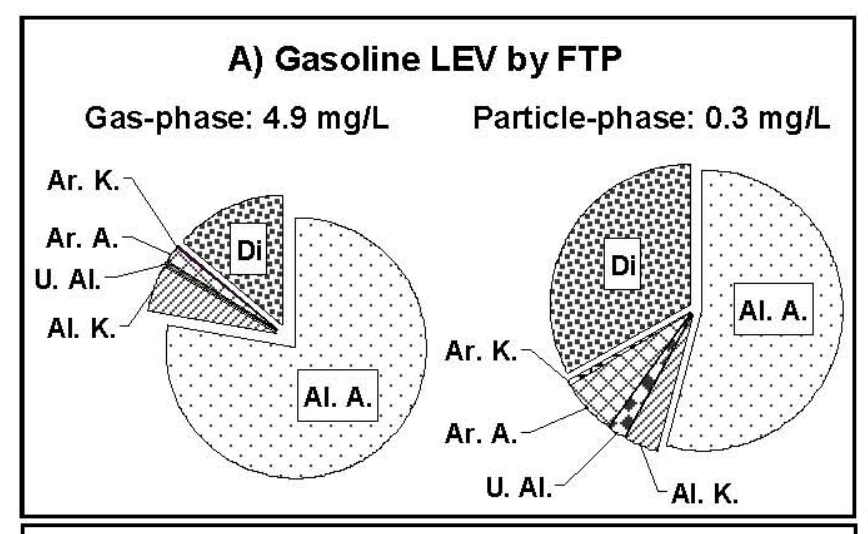

C) Diesel 1999 HHDDT

Gas-phase: $38 \mathrm{mg} / \mathrm{L} \quad$ Particle-phase: $6.4 \mathrm{mg} / \mathrm{L}$

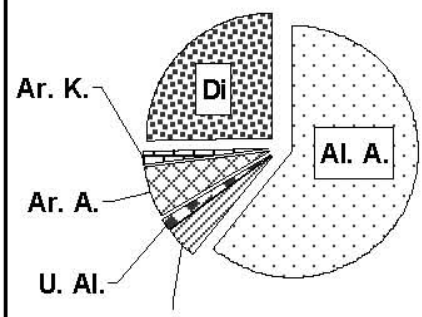

Al. K.

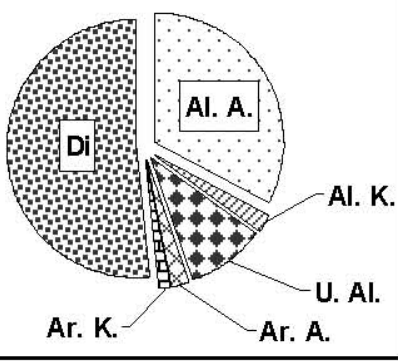

B) Gasoline TWC by FTP

Gas-phase: $6.7 \mathrm{mg} / \mathrm{L} \quad$ Particle-phase: $1.6 \mathrm{mg} / \mathrm{L}$

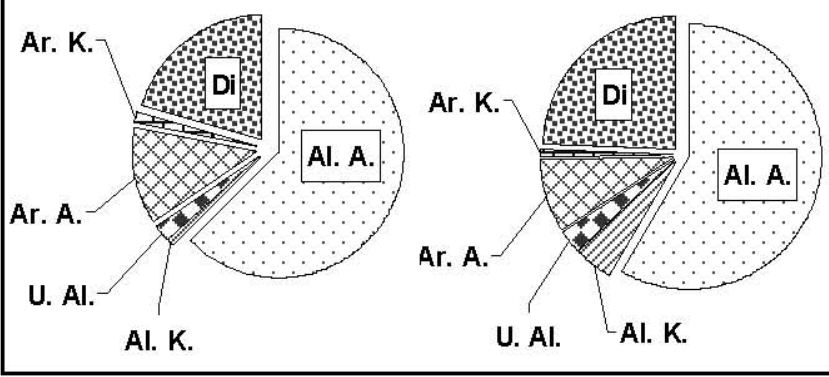

D) Diesel 1999 Idle-creep

Gas-phase: $98 \mathrm{mg} / \mathrm{L} \quad$ Particle-phase: $13 \mathrm{mg} / \mathrm{L}$

Ar. $\mathrm{K}$.

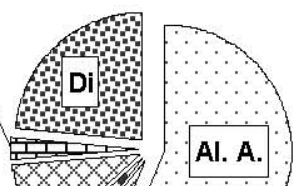

Ar. K.

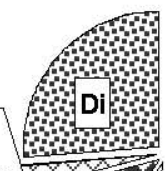

Ar. A.

Ar. A.

U. Al.

U. Al.

Al. $\mathrm{K}$.

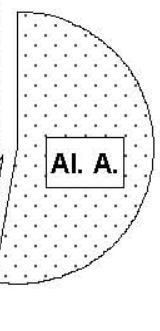
Al. A. = Aliphatic Aldehydes
Al. K. = Aliphatic Ketones
U. Al. = Unsaturated Aliphatics
Ar. $A .=$ Aromatic Aldehydes
Ar. $\mathrm{K}$. = Aromatic Ketones
Di $=$ Dicarbonyls

Figure 3 


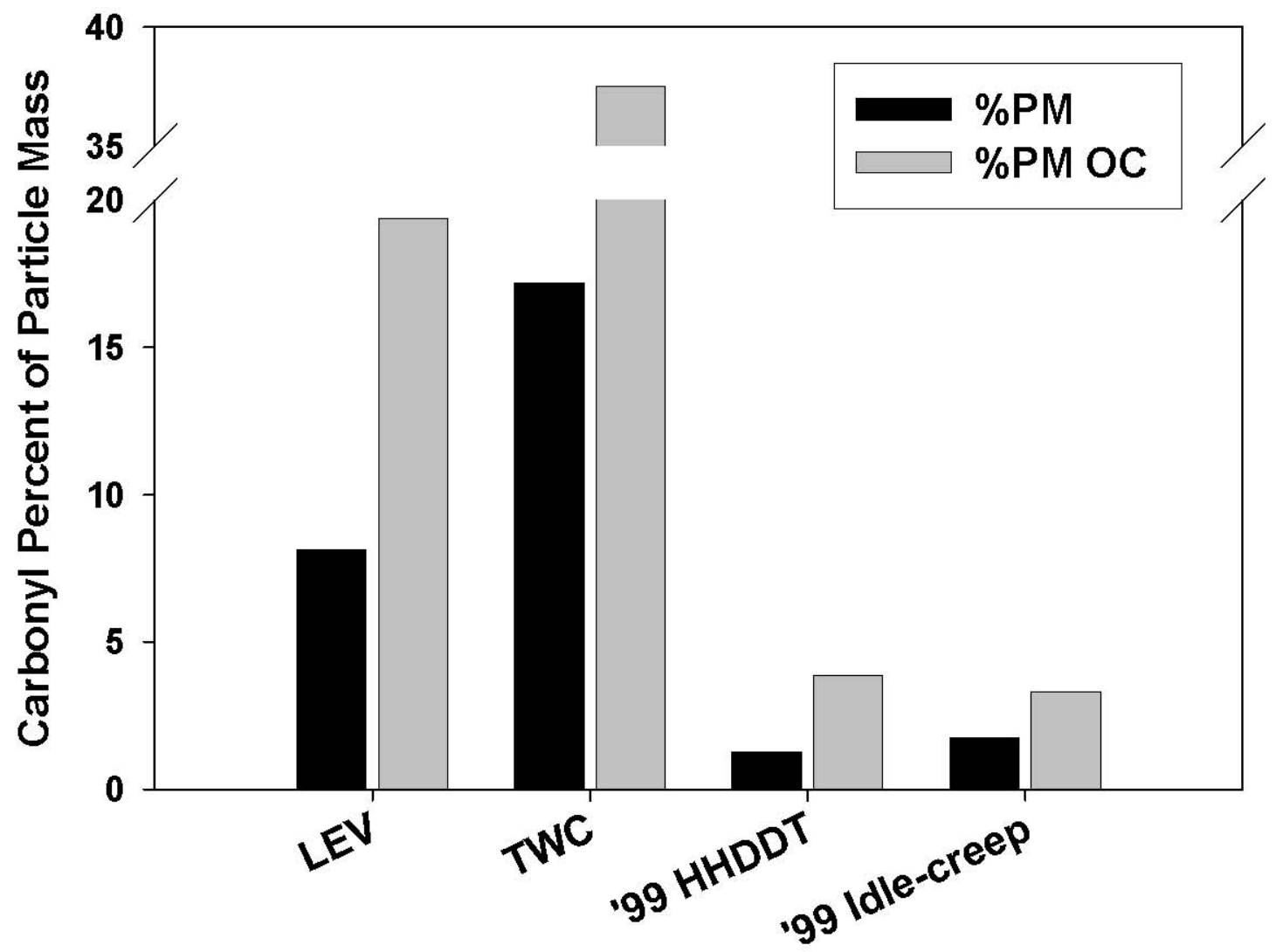

Figure 4.

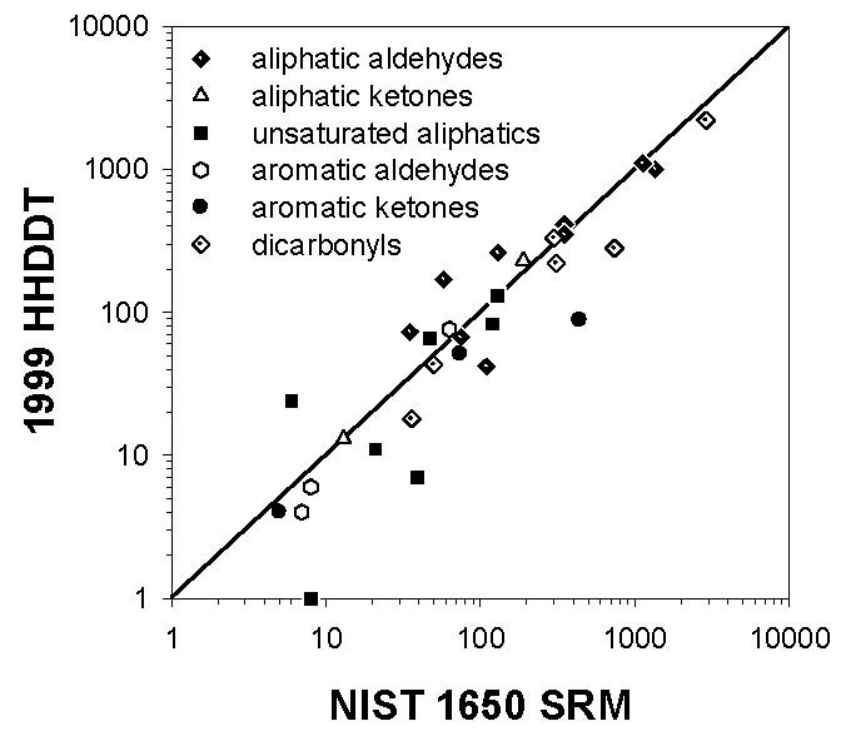

Table Captions

Table 1. Phase speciated carbonyl emission factors from low emission and three-way catalyst light-duty vehicles operated under the FTP driving cycle and a 1999 Freightliner tractor operated under Idle-creep and the HHDDT driving cycle conditions, note fuel 
efficiency factors are provided in (italics). Fuel efficiency factors (italics, $\mathrm{km} \mathrm{L-l}$ ) are shown to allow conversion to distance-based emission factors. Chemical structures for the most abundant species within each compound class are provided.

\section{Table 1}


Emission Rate a $\left(\mu \mathrm{g} \mathrm{L}^{-1}\right)$ for Gas-Phase $(\mathrm{G})$ and Particle-Phase $(P)$ Carbonyls

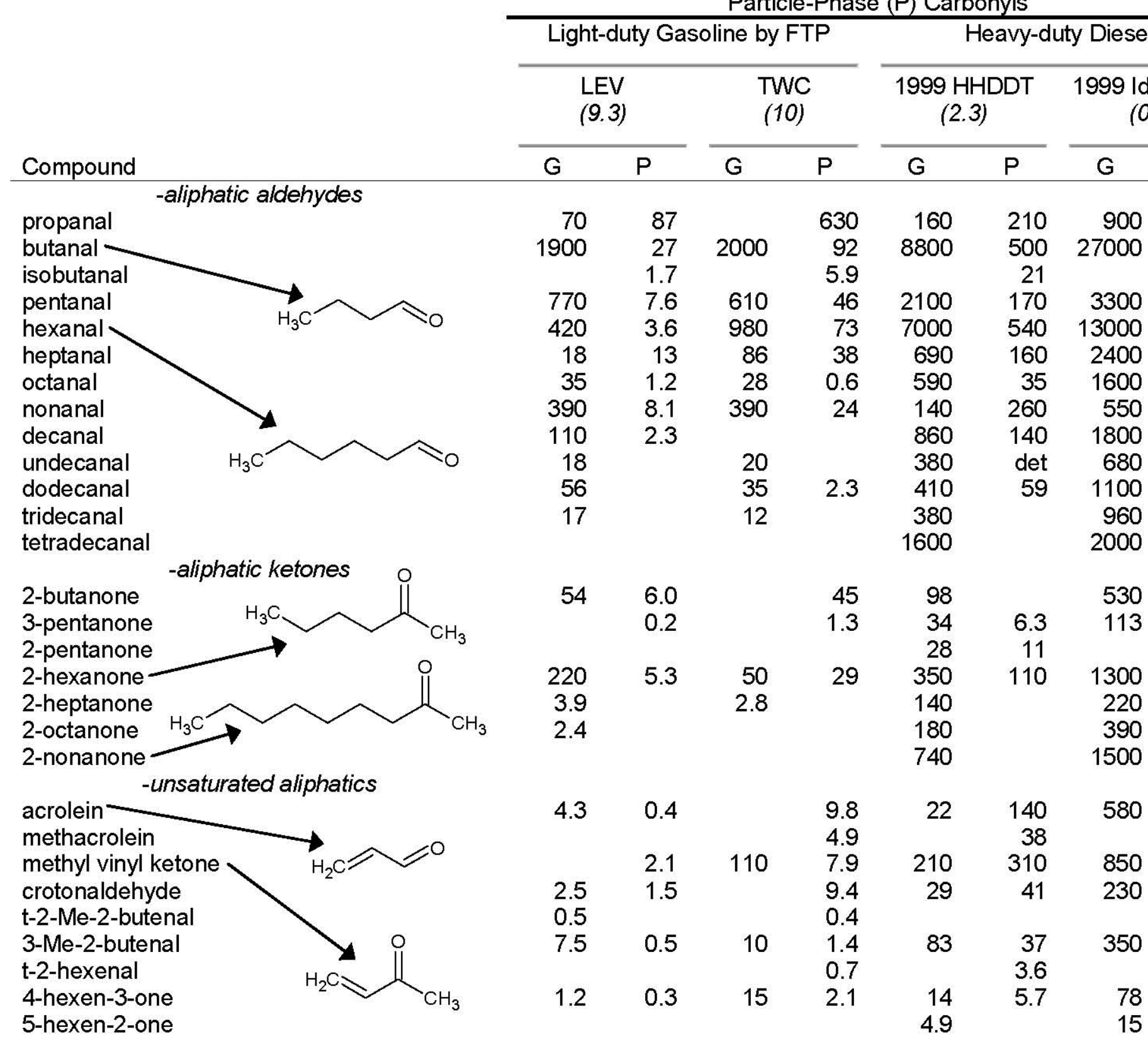




\section{-cyclic aliphatics}

2-Me-2-cyclopentenone

3-Me-2-cyclopentenone

2-cyclohexenone

-aliphatic dicarbonyls

glyoxal

methyl glyoxal<smiles>CCC1C=C(C)CC1</smiles>

2,3-butanedione

2,3- and 2,4-pentanedione

2,3-hexanedione

2,5-hexanedione

-aromatic aldehydes

benzaldehyde

dehyde

o- \& m-tolualde

t-cinnamaldehyde

3,4-Me-benzaldehyde

2-Et-benzaldehyde

4-Et-benzaldehyde

1-naphthaldehyde

2-naphthaldehyde<smiles>O=Cc1ccc2ccccc2c1</smiles><smiles>O=Cc1ccccc1</smiles>

4-biphenylcarboxaldehyde

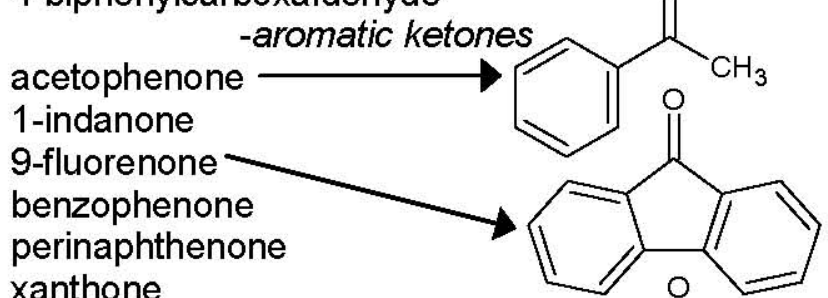

xanthone

-aromatic dicarbonyls ${ }^{\mathrm{h}}$

1,2-Ac-benzene

1,3-Ac-benzene

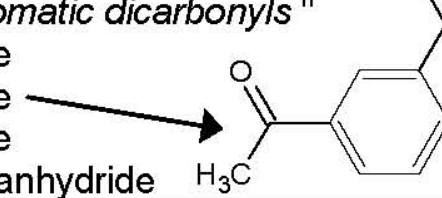

1,4-Ac-benzene

1,8-naphthalic anhydride $\mathrm{H}_{3} \mathrm{C}$<smiles>C=C(C)C</smiles>

0.7

1.6

2.0

0.1

1.4

10

det

2.5
21

550

\section{$\begin{array}{ll}7.9 & 37.8\end{array}$}

46

0.4

det

55

23

32

4.1

770

9.7

\section{5}

4.3

4.0

380

42

9.5

100

150

260

15

190

45

62

9.3

10

$\begin{array}{lll}4.0 & 1.2 & 28 \\ 5.7 & & 31 \\ 2.9 & 0.3 & 29 \\ 1.7 & 0.7 & 0.7\end{array}$

28

29

0.7

41

18

11

7.9

\section{3}

3.5

det

\section{0}

250

6.6

det

40

19

17

47

65

9.7

9.7

130

500

230

380

100

$\begin{array}{rr}13 & 230 \\ & 75 \\ \operatorname{det} & 190\end{array}$

2.3

2.0

Analytes that were observed at a signal:noise ratio below 10:1 but above 3:1 are listed as detected (det), em either the species was not observed or the sampled concentration was insignificant in relation to the backgrou b Corrected for recovery of 2-F-benzaldehyde, ${ }^{\mathrm{C}}$ Gas-phase corrected for recovery of 5-F-1-indanone, particlefor recovery of 8-F-1-benzosuberone, ${ }^{d}$ Corrected for recovery of 4-F-benzophenone, ${ }^{e}$ Compound was quanti underivatized form, ${ }^{f}$ Compound was quantified as PFB oxime using LC-MS, ${ }^{g}$ Identification is based on relativ to homologous 2-ketones and the authentic standard 3-nonanone, ${ }^{\mathrm{h}}$ Note that emissions of quinones were rep et al., 2007

\section{BRIEF}

Carbonyl compounds present in motor vehicle exhaust, ranging from $\mathrm{C}_{2}$ to $\mathrm{C}_{13}$, comprise a substantial fraction of light-duty gasoline vehicle particulate matter emissions. 